\title{
Progressivity of the Output Based Aid Voucher Programme and its Effects on Family Planning and Maternal Health in Nairobi and Kiambu Counties, Kenya
}

\author{
Isaac Odeyovwi Ogo, MSc \\ Health Economics and Policy, School of Economics, \\ University of Nairobi, Kenya \\ Urbanus M. Kioko, PhD \\ School of Economics, University of Nairobi, Kenya
}

Doi:10.19044/esj.2020.v16n25p175 URL:http://dx.doi.org/10.19044/esj.2020.v16n25p175

\begin{abstract}
Introduction: In developing countries, the poor and vulnerable are unable to access basic healthcare needs due to health financing related constraints. Healthcare needs are mostly financed through out of pocket, resulting in catastrophic expenditure. In 2006, the government of Kenya in partnership with Kfw implemented the Output-Based Aid (OBA) voucher programme to increase access for family planning and birth delivery in four counties in Kenya. However, evidence on the progressivity of the Output Based Aid voucher and its impact on FP and maternal healthcare services in Kenya is limited. The objective of this study was to examine progressivity of the OBA voucher programme and its effect on Long Term Family Planning methods and maternal health in Nairobi and Kiambu Counties of Kenya. The study adopted a case study research design, using data obtained from Kenya Ministry of Health (MOH).The Benefit Incidence Analysis (BIA) and binary probit regression model was used to analyse progressivity of the OBA voucher programme and its effect on Family Planning and Maternal Health. The findings showed that the OBA voucher programme was regressive because it did not benefit poor women. However, the study revealed that the OBA voucher programme had a positive effect on the utilization of maternal health across the two counties. Based on the findings, this study can be used to inform the design and implementation of the UHC particularly by ensuring that financing of family planning and maternal health services is progressive.
\end{abstract}

Keywords: Progressivity, Benefit Incidence Analysis, Output-Based Aid Voucher, Family Planning and Maternal Health 


\section{Introduction}

Fertility and maternal health outcomes are indices and determinants of measurement of societal wellbeing critical in determining growth and sustained economy (Bhargava, 2007). Low fertility is associated with welfare improvement of women and children. It allows mothers more time and resources to cater for their children and improve their Reproductive Health, $\mathrm{Wu}$ (2009) and Ncece, (2017). Reproductive Health in this context is defined from wider health perspective (WHO, 2000). This perspectives places high premium on choice and equips women with rights to regulate their fertility as well as improve their access to healthcare and health equity (Richard et al., 2016).

Globally, 221 million women desire to prevent unintended pregnancies, but are unable to do so (UNFPA, 2016). In low income countries, women are unable to prevent pregnancy because of cost of accessing contraceptives. The high cost of providing maternal healthcare and the catastrophic expenditure on the household, increases poverty (Myint et al., 2018). In Kenya, about $37 \%$ of women deliver at home or fail to seek care in time (KDHS, 2014, Abuya, Njuki, et al., 2012). Furthermore, Out-Of-Pocket (OOP) expenditure increases delays in seeking care, complicate childbirth and increases inequity in health. Njuki et al., (2015); Richard, et al., (2016) and Oyugi et al., (2017) argues that access to family planning services not only enhances healthy equity but also averts 30\% maternal death averted annually.

Access to maternal health and family planning services continue to attract interest globally and especially among developing countries because of its associated challenges of health financing (Schellenberg, Victora, et al., 2003; Meuwissen, et al., 2006; Ir, Horemans, et al., 2010; Ologunde et al., 2014). According to Tulchinsky and Varavikova, (2014) and Atanasova et al., (2016) Machio, M. P. (2008), adequate and affordable healthcare system is required to attain Universal Health Coverage (UHC). However, health financing systems in Africa and indeed Kenya is far from adequate to address equity and catastrophic expenditure (Munge and Briggs, 2014).

To achieve health care needs in line with the goal of UHC, the Kenya government in partnership with the German Development partners (BMZ and KfW) employed a demand side financing (DSF) Output-Based Aid (OBA) voucher programme in 2006, to subsidize reproductive health services to poor women through voucher programme. The programme was a performancebased reproductive health voucher scheme to reduce Out-of-Pocket Expenditure (OOPE) by improving the healthcare necessities of women as well as improve access to safe motherhood. Reviewing the outcome of the programme, Obare, et al., (2013) and Murray et al., (2014) are of the view that the voucher health financing programmes improved healthcare needs of 
women through increased deliveries by skilled birth midwife, increased uptake of LTFP methods, improve quality of care and access to healthcare.

Other assessment of the programme after it ended indicates that the programme increased utilisation of reproductive health services in Kenya (KfW, 2012; Mwangangi, 2017; Oyugi, et al., 2018). Some other studies explored progressivity of health financing systems for non-reproductive healthcare services (Akazili et al., 2012; Munge \& Briggs, 2013). However very few studies, if any, have been done to determine progressivity of the Output Based Aid voucher and the impact of the programmes on FP and maternal healthcare services in Kenya. This study therefore addresses this knowledge gap by determining progressivity of OBA voucher programme on family planning and maternal healthcare services in Kenya.

\section{Literature Review}

Several studies have pointed out poor people are unable to access basic healthcare needs including family planning and maternal health services because of health financing constraints (Bhutta et al., 2013) and O'Donnell et al., (2007). Cognizant of these challenges, the Kenya government in partnership with the German Development partners (BMZ and KfW) introduced a demand side financing (DSF) OBA voucher programme in 2006, to subsidize reproductive health services among poor women (Eva et al., 2015). The OBA voucher programme was a performance-based reproductive health voucher scheme. The aim of the programme was to reduce Out-ofPocket Expenditure (OOPE) by improving the healthcare of women as well as improve access to safe motherhood. Reviewing the outcome of the programme, Obare, et al., (2013) and Murray et al., (2014) noted that the voucher programmes had increased deliveries by skilled birth midwife, increased uptake of Long Term Family Planning (LTFP) methods and quality of care.

Further evidence suggests that voucher subsidy programmes increase health service use and improve quality of service offered to groups of people (Bellows et al., 2011; Meyer et al., 2011). A study in Bangladesh and Pakistan on the effect of voucher schemes on sexual and reproductive health revealed that the programmes lowered inequity in access to healthcare through raising demand among the poor more than the non-poor (Ahmed and Khan, 2011; Agha, 2011; Agha, 2011 and Nguyen, et al., 2012). Similar studies by Bellows et al., (2012), Obare et al., (2014), Mwangangi, (2017) and Oyugi, et al., (2018) showed that the voucher increased uptake of reproductive and family planning services.

In Ghana, progressivity of health system financing as well as the incidence of service benefits indicates that healthcare financing system in the country was driven by progressivity of taxes (Akazili et al. 2012). In Kenya, 
Oyugi et al., (2017) examined access to Long Term Family Planning (LTFP) methods. The study compared OBA clients with non-OBA clients in facilities supported by voucher programme. The result showed statistically significant differences in the mean use of LTFP between OBA clients versus non-OBA clients. A quasi-experimental assessment of the OBA programme revealed that there was a causal link between voucher programme and quality of healthcare after delivery among groups in Kenya (Watt et al., 2015). Obare, et al., (2014) also explored the impact of vouchers on assisted skilled birth and found that the voucher schemes reduced the proportion of women in the community who were exposed to Out-of-Pocket expenditure (OOP) for safe motherhood services.

Munge and Briggs (2013) assessed proportionality of progressivity deviations between diverse healthcare financing sources with respect to payment capability. Using Kakwani index, the study revealed that healthcare financing structures were regressive. Other studies have pointed out that voucher programme addresses equity in accessing reproductive healthcare among the poor and vulnerable groups (Bellows et al., 2011 and Meyer et al., 2011). While evidence on the effect of OBA voucher programme on utilisation of family planning and maternal health care is readily available, studies on the progressivity of the OBA demand side financing are lacking. Most of them have concentrated on modelling healthcare financing system with little focus on modelling progressivity of programme-based healthcare services (Akazili et al., 2012; Munge and Briggs 2013).

From the review of the literature, it is evident that voucher programme addresses equity in accessing reproductive healthcare among the poor and vulnerable groups (Bellows et al., 2016 and Meyer, Bellows et al., (2011). Evidence also suggest that voucher health programme increases equity in healthcare services and insulate the poor against catastrophic health spending. Thus, according to Oyugi et al., (2017), "increase in healthcare equity, is a cornerstone for achieving universal health coverage". Despite the increased health subside programme, there is still large gaps in access to healthcare (reproductive health) among the poor and vulnerable (Barros, Ronsmans, et al., 2012). Some scholars are of the view that competition in voucher programs improves health equity (Abuya, et al., 2012; Grainger, et al., 2017). Most studies employed logistic regressions or linear regression analysis to examine the effect of voucher programme on reproductive health services. Other studies such as have relied on basic qualitative assessments and not econometric estimation. On progressivity, studies including Akazili et al., (2012) and Munge and Briggs (2013) have concentrated on modelling healthcare financing system with little focus on modelling progressivity of programme-based healthcare services. However, few studies have been conducted using benefit incidence analysis to establish whether there is 
progressivity of the voucher OBA programme. In this study, the question is, does the voucher programme benefit poor or a significant proportion, or disproportionate proportion benefits the well off?

\section{Materials and Methods}

\subsection{Benefit Incidence Analysis}

To realize the first objective of this study, the study derives progressivity of the OBA voucher program by employing the Benefit Incidence Analysis (BIA). The specific public subsidy provided to an individual is rewritten as:

$$
S_{k i}=q_{k i} c_{k j}-f_{k i}
$$

Where $S_{k i}$ is public subsidy; $q_{k i}$ represent number of service k spent by people $\mathrm{i}$; and $c_{k j}$ represent the cost of providing $\mathrm{k}$ in the region $\mathrm{j}$ where individual $\mathrm{i}$ is located. Lastly, $f_{k i}$ is the fee paid for $\mathrm{k}$ by $\mathrm{i}$ (the unit cost calculated by obtaining a proportion of total recurrent spending to total units used).

O'Donnell et al., (2007) suggests the total public subsidy obtained by an individual can be represented as:

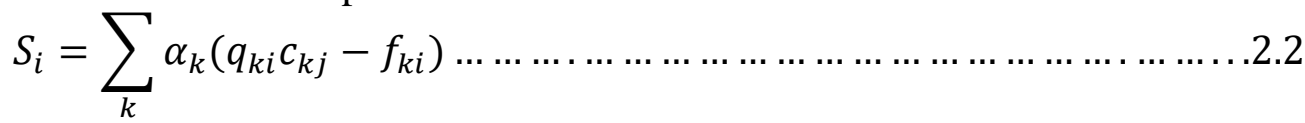

Where: $\alpha_{k}$ is a constant of proportionality that standardizes usage recall periods across services. In this study, the recall period for the OBA services (maternal health and family planning utilization) is required to be considerably longer such that the items or subjects observed (in this case women using these services) is not very small but at the same time not too long in that the recall biases is huge. On the other hand, if the available information provides the total amount paid to all public health services at the aggregation level, then equation 2 can be modified as:

$$
\begin{array}{r}
S_{i}=\sum_{k} \delta_{k} q_{k i} c_{k j} \\
-f_{i}
\end{array}
$$

Where $f_{i}$ represents the amount paid in all accredited healthcare facilities, whereas $\delta_{k}$ is the scaling factor. It normalises the recall periods on variables linked to treatment and healthcare use for the recall period and applicable to the variable(s) indicating all payment. The objective is to make sure that subsidy benefits the poor. When this happens, the subsidy concentration curve must dominate the 45 -degree line. If subsidies incorporate 
part of the individuals' final income, then alternative distributional goals may be evenly distributing the final income more than pre-subsidy income.

Through equation 2 and 3, progressivity of the subsidy is derived from the concentration curve, which is double the area between the concentration curve and the Lorenz curve. This is used as an immediate measure of retrogressive or progressive (Kakwani, 1977) also known as the Kakwani index. This is expressed as $\pi_{k}=C-G$; where $\mathrm{C}$ is subsidy concentration index and $\mathrm{G}$ is the Gini coefficient of the measure for the living standard. The $\pi_{k}$ value ranges between minus two (-2) and one (1). It is negative (positive) if the concentration curve dominates (is dominated by) the Lorenz curve. However, where the concentration lies on top of the Lorenz curve, the Kakwani index is zero.

The value of Kakwani index s expressed in the following form.

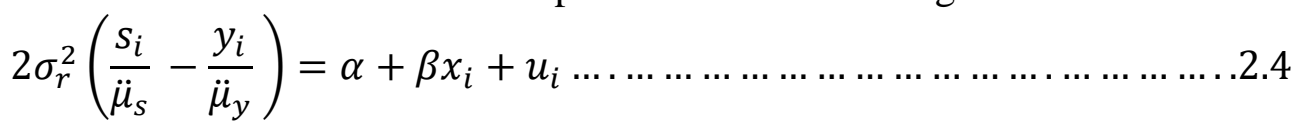

Where $s_{i}$, represents subsidy of health service provided to client $i$; $\ddot{\mu}_{s}$ represent estimate of its mean; $y_{i}$ represent the living standard measure, $\ddot{\mu}_{y}$ represent, estimate of its mean, $r_{i}$ represent, the weighted fractional rank of the living standards distribution and $\sigma_{r}^{2}$ represent its variance. The use of Ordinary Least Squares (OLS) elucidates $\beta$ which is an estimate of the Kakwani index (Demery and Gaddis, 2009). This is, however, equivalent to estimation of the percentage shares and their variance matrix as well as joint estimation across multiple outcome variables or sub-populations (Jann, 2016).

Further, considering service volume, and the cost of services received, benefits for service delivered were estimated by type of service, such as family planning and maternal health. These subsidies (benefits) were then disseminated following the living standard of the women gaining the said benefits. The study thus employed Lorenz curves and concentration curves which, according to Jann (2016) are widely used tools for the analysis of economic inequality and redistribution. According to Jann (2016) on contrasts, we computed the distributional differences. This aids in evaluating whether distribution say $W$ Lorenz dominates distribution $Z$. Further, the difference that is GLw ( $p)$-GLz $(p)$ could be used to determine whether distribution $W$ generalized Lorenz dominates distribution $Z$. Note that dominance is given if the difference is positive for all $p$. 


\subsection{Empirical model for estimating effect of OBA on utilisation of FP and deliveries}

A binary probit model was used in the analysis of the effect of OBA voucher programme on the utilisation of family planning and deliveries. The probability of using or not using family planning or maternal health services is a function of a vector of OBA vouchers (Xi) and a vector of household's socioeconomic characteristics $(\mathrm{Ri})$, and a stochastic error term $\left(\varepsilon_{i}\right)$. The latter component captures errors in model specification (e.g. omission of relevant variables) and errors in data measurement. Algebraically, the demand for family planning services and maternal health services can be expressed as:

$$
Y=g\left(X_{i j}, R_{i}\right)+\varepsilon
$$

where: $\mathrm{Y}$ is the likelihood of receiving FP and $\mathrm{MH}$ service is 1 if one utilizes; and 0 when otherwise; $\mathrm{X} \mathrm{ij,} \mathrm{Ri} \mathrm{and} \varepsilon$ are as defined above.

To determine the effect of OBA vouchers on utilisation of family planning services and maternal health, the following model was estimated:

$Y i=(\alpha+\beta 1$ OBA subsidy $+\beta 2$ Age of the woman $+\beta 3$ Education $+\beta 4$ Marital status $+\beta 5$ Wealth quintiles $+\beta 6$ Exposure to mass media $+\varepsilon i \ldots 2.6$

Where: $Y_{i}=$ A dummy variable for demand of reproductive health by women where $\mathrm{i}=1$ for family planning or maternal health and equals; $(\alpha)$ is the intercept term; $(\beta$ 's) are the estimated coefficients; and $\varepsilon \mathrm{i}$ is the stochastic error term. The explanatory variables included in the models are defined in Table 1.

\subsection{Data and Definition of Variables}

\subsubsection{Data}

The data for empirical analysis were taken from the database of the ministry of health. The data was derived from a sample of 20,000 women of reproductive age (15-49 years) who benefited from the OBA voucher programme across the 58 health facilities in Nairobi (Viwandani and Korogocho) and Kiambu counties. These women accessed reproductive health services in public, private hospitals, or Non-Governmental Organizations (NGO) healthcare facilities that were accredited to implement the OBA programme. The OBA data was rich with economic, demographic, social characteristics of the OBA clients, maternal health care services (hospital deliveries), family planning (clinical methods), costs per client and services.

\subsubsection{Variables}

Table 1 provides definitions and measurements of the variables used in estimations. 
Table 1. Definition of variables

\begin{tabular}{|c|c|c|}
\hline Variables & Definitions and measurement & Expected Effects \\
\hline $\begin{array}{l}\text { Family Planning } \\
\text { (Model 1) }\end{array}$ & $\begin{array}{l}\text { Dependent variable: } 1=\text { women of reproductive } \\
\text { age who accessed and utilized any of family } \\
\text { planning products under OBA voucher } \\
\text { programme and 0; Otherwise }\end{array}$ & 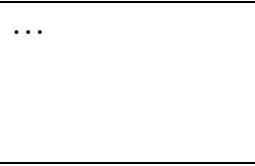 \\
\hline $\begin{array}{l}\text { Maternal Health } \\
\text { (model 2) }\end{array}$ & $\begin{array}{l}\text { Dependent variable: } 1=\text { women of reproductive } \\
\text { age who accessed and utilized maternal } \\
\text { healthcare services (birth deliveries) under the } \\
\text { OBA voucher programme and 0; otherwise. }\end{array}$ & $\cdots$ \\
\hline $\begin{array}{l}\text { Age of the } \\
\text { Woman }\end{array}$ & Respondent's age in years & Positive \\
\hline Age squared & Respondent's age squared & Positive \\
\hline Marital Status & $1=$ if married; $0=$ single, separated or divorced & \\
\hline Education & $\begin{array}{l}\text { Respondent's education level: } 1=\text { no education } \\
\text { (reference variable), } 2=\text { primary education level, } \\
3=\text { secondary education level, } 4=\text { Higher level of } \\
\text { Education }\end{array}$ & Positive/Negative \\
\hline Wealth Quintiles & $\begin{array}{l}1=\text { poorest (reference), } 2=\text { poorer, } 3=\text { middle, } 4= \\
\text { rich, and } 5=\text { richest. }\end{array}$ & Positive \\
\hline $\begin{array}{l}\text { Employment } \\
\text { Status }\end{array}$ & $1=$ if employed $; 0=$ otherwise & Positive \\
\hline $\begin{array}{l}\text { Subsidy levels } \\
\text { under OBA } \\
\text { voucher }\end{array}$ & $\begin{array}{l}\text { It is the difference in cost of obtaining FP and } \\
\text { MH service and the actual amount paid }\end{array}$ & Positive \\
\hline $\begin{array}{l}\text { Exposure to } \\
\text { Mass Media }\end{array}$ & $\begin{array}{l}1=\text { if exposed to any mass media channel; } 0 \\
\text { otherwise. }\end{array}$ & Positive \\
\hline
\end{tabular}

\section{Results}

\subsection{Descriptive statistics}

Table 2 presents the frequency and percentage distribution of the dependent and independent variables. Overall, 23\% of the women in the sample had accessed family planning services. About 39\% of the women delivered in a health facility. In the overall sample, the mean OBA subsidy was Kshs 3542 with a standard deviation (STD) of Kshs 2862. The mean age of the respondents was 29 years with a standard deviation of 9.4 years. Fifty five percent of the women in the sample were married, $52 \%$ had no education at all while $17 \%$ attained primary school level of education. Those who had attained secondary and tertiary education were $24 \%$ and $6.5 \%$ respectively. Considering the wealth quintiles, majority of the respondents were in the first (Mean=24.3\%) and fifth (Mean=21.2\%,) wealth quintiles. The differences between the second, third and fourth quintiles were small and thus negligible. Finally, about $61 \%$ of the respondents had access to mass media (radio, TV or read newspaper). 
Table 2: Analytic Sample Characteristics

\begin{tabular}{|l|l|l|l|}
\hline \multicolumn{1}{|c|}{ Variables } & Observations & \multicolumn{1}{c|}{ Mean } & Std Dev \\
\hline Family Planning & 19,982 & 0.23 & 0.42 \\
\hline Birth Deliveries & 20,000 & 0.39 & 0.49 \\
\hline Subsidies (OBA) & 20,000 & 3542 & 2862.16 \\
\hline Age & 20,000 & 29.11 & 9.40 \\
\hline Age Squared & 20,000 & 936.21 & 581.91 \\
\hline Marital Status & 20,000 & 0.55 & 0.50 \\
\hline Education: & & & \\
\hline None & 20,000 & 0.52 & 0.50 \\
\hline Primary & 20,000 & 0.20 & 0.40 \\
\hline Secondary & 20,000 & 0.24 & 0.43 \\
\hline Higher/Tertiary & 20,000 & 0.07 & 0.25 \\
\hline Marital Status & 20,000 & 0.55 & 0.50 \\
\hline Wealth Quintiles: & & & \\
\hline $1^{\text {st }}$ quintile & 20,000 & 0.24 & 0.43 \\
\hline $2^{\text {nd }}$ quintile & 20,000 & 20,000 & 0.38 \\
\hline $3^{\text {rd }}$ quintile & 20,000 & 0.17 & 0.38 \\
\hline $4^{\text {th }}$ quintile & 20,000 & 20,000 & 0.39 \\
\hline $5^{\text {th }}$ quintile & 20,000 & 0.21 & 0.41 \\
\hline Employment & 9,148 & 0.56 & 0.50 \\
\hline Exposure to Mass Media & 20,000 & 0.61 & 0.49 \\
\hline
\end{tabular}

\subsection{Benefit Incidence Results}

The study focused on women who were in the bottom 20 of the wealth quintiles. The coefficient on women in the first $(0-20)$ wealth quintile was positive $(\beta=4.4)$ and statistically significant at $5 \%$ level. This implies that women in this quintile enjoyed $4.4 \%$ of the OBA subsidies while those in the remaining quintiles accounted for $95.6 \%$ of the subsidies. The coefficient on the second (20-40) wealth quintile was positive and statistically significant at the $5 \%$ level $(\beta=10.73, \mathrm{t}=164.6)$. This shows that only $10.7 \%$ of the OBA subsidies benefitted women in the second quintile. The results further showed that the coefficient on women in the third or middle (40-60) wealth quintile was positive $(\beta=17.07)$ and statistically significant at $5 \%$ level, implying that women in this wealth index received $17.1 \%$ of the OBA services. In the fourth $(60-80)$ wealth quintile $(\beta=25.5, \mathrm{t}=235)$ women by $25.5 \%$ of the OBA services. Given that the OBA subsidies were meant to benefit the poor women, this category of OBA clients were not intended to benefit from the OBA subsidies. The results further revealed that women in the fifth (80-100) wealth quintile $(\beta=42.25, \mathrm{t}=192.66)$ significantly benefited by $42.3 \%$ of the OBA services, implying that the OBA services benefitted women in the fourth and fifth wealth quintiles. 
These results demonstrate that OBA voucher programme was regressive to the poor women, yet the programme was expected to benefit the poorest women in the two counties. The fact that the top 20\% (80-100) of women in the fifth wealth quintile received about $43 \%$ of OBA subsidies, then the OBA voucher programme was highly regressive.

Table 3: Benefit Incidence Analysis (Quintiles Shares in Percentages)

\begin{tabular}{|c|c|c|c|c|c|}
\hline Subsidies & Coefficients & Std. Err. & t-stat & \multicolumn{2}{|c|}{ [95\% Conf. Interval] } \\
\hline \multicolumn{6}{|l|}{$1^{\text {st }}$ Quintile } \\
\hline $0-20$ & 4.17 & 0.11 & 37.15 & 3.95 & 4.39 \\
\hline $20-40$ & 11.29 & 0.13 & 88.96 & 11.05 & 11.54 \\
\hline $40-60$ & 15.29 & 0.17 & 88.00 & 14.95 & 15.64 \\
\hline $60-80$ & 26.55 & 0.24 & 110.45 & 26.08 & 27.02 \\
\hline $80-100$ & 42.69 & 0.44 & 97.17 & 41.83 & 43.55 \\
\hline \multicolumn{6}{|l|}{$2^{\text {nd }}$ Quintile } \\
\hline $0-20$ & 3.88 & 0.12 & 31.84 & 3.64 & 4.12 \\
\hline $20-40$ & 10.34 & 0.19 & 53.75 & 9.96 & 10.72 \\
\hline $40-60$ & 18.51 & 0.28 & 66.90 & 17.96 & 19.05 \\
\hline $60-80$ & 25.68 & 0.32 & 80.64 & 25.05 & 26.30 \\
\hline $80-100$ & 41.60 & 0.53 & 77.87 & 40.55 & 42.65 \\
\hline \multicolumn{6}{|l|}{$3^{\text {rd }}$ Quintile } \\
\hline $0-20$ & 4.19 & 0.13 & 31.59 & 3.93 & 4.45 \\
\hline $20-40$ & 10.96 & 0.19 & 58.21 & 10.59 & 11.33 \\
\hline $40-60$ & 17.38 & 0.18 & 96.45 & 17.03 & 17.73 \\
\hline $60-80$ & 25.57 & 0.24 & 106.06 & 25.09 & 26.04 \\
\hline 80-100 & 41.90 & 0.52 & 80.61 & 40.88 & 42.92 \\
\hline \multicolumn{6}{|l|}{$4^{\text {th }}$ Quintile } \\
\hline $0-20$ & 4.75 & 0.13 & 36.99 & 4.50 & 5.00 \\
\hline $20-40$ & 11.06 & 0.17 & 66.27 & 10.73 & 11.38 \\
\hline $40-60$ & 17.53 & 0.16 & 108.53 & 17.21 & 17.84 \\
\hline $60-80$ & 24.90 & 0.24 & 105.78 & 24.43 & 25.36 \\
\hline $80-100$ & 41.77 & 0.47 & 88.62 & 40.84 & 42.69 \\
\hline \multicolumn{6}{|l|}{$5^{\text {th }}$ Quintile } \\
\hline $0-20$ & 5.35 & 0.13 & 42.66 & 5.11 & 5.60 \\
\hline $20-40$ & 11.54 & 0.16 & 72.23 & 11.23 & 11.86 \\
\hline $40-60$ & 17.60 & 0.18 & 98.87 & 17.26 & 17.95 \\
\hline $60-80$ & 22.38 & 0.23 & 98.06 & 21.94 & 22.83 \\
\hline $80-100$ & 43.11 & 0.49 & 88.08 & 42.15 & 44.07 \\
\hline \multicolumn{6}{|c|}{ Total (Aggregated) } \\
\hline $0-20$ & 4.44 & 0.06 & 75.63 & 4.33 & 4.56 \\
\hline $20-40$ & 10.73 & 0.07 & 164.64 & 10.60 & 10.86 \\
\hline $40-60$ & 17.07 & 0.07 & 234.94 & 16.93 & 17.21 \\
\hline $60-80$ & 25.50 & 0.11 & 235.27 & 25.29 & 25.72 \\
\hline $80-100$ & 42.25 & 0.22 & 192.66 & 41.82 & 42.68 \\
\hline
\end{tabular}

Figure 1 shows the Gini index which is represented by the area between the Lorenz curve and a hypothetical line of absolute equality. The Gini index of 0 represents perfect equality, while an index of 100 represent 
perfect inequality. Overall, the programme demonstrates moderate inequality given the (total) Gini coefficient was 0.39. This characteristic was also observed across the five categories of wealth quintiles.

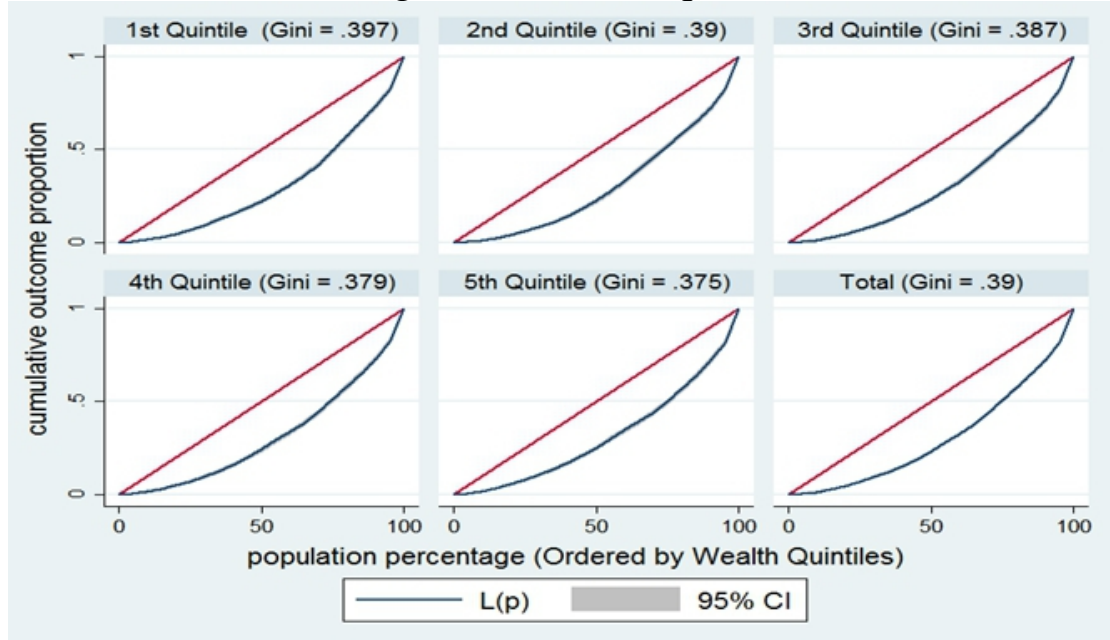

Figure 1: Lorenz Curves and Gini Coefficients

The study further explored the contrasts and Lorenz dominance. A useful feature of Lorenz curve is that contrasts between sub-populations (or outcome variables) that can be computed. The study evaluated whether the subsidy distribution of women from other wealth quintiles dominates the subsidy distribution of women from lowest quantiles (poorest). The findings are as shown in figure 2 [details in the appendix]. We compute the distributional differences of the coefficient estimates for four wealth quintiles against the first wealth quintile (poorest) as well as the overall socioeconomic status (total). Dominance is given if the difference is positive for all p. Figure 2 shows the difference in the coefficient estimates in 2nd-fith quintiles against the first wealth quintile (poorest) as well as the overall socioeconomic status.

The second wealth quintile shows a negative difference with coefficients ranging between 0.00083 and 0.01426 . This implies that there is no dominance of the second wealth quintile on the first wealth quintile for the bottom $45 \%$. These characteristics were also observed in the top $15 \%$ of poor women. The third wealth quintile demonstrated similar trend as the second wealth quintile for the bottom $45 \%$ and the top $15 \%$. In the fourth wealth quintile, there was no dominance between $85 \%$ and $90 \%$. However, at $95 \%$, dominance was positive. The fifth wealth quintile had a negative difference and thus no dominance, implying that the fifth wealth quintile dominates the first wealth category for the top $20 \%$. Consequently, the finding of the study indicate that OBA was regressive to the poorest of the poor; and therefor, there is need for redirection to address the poorest of the poor. 


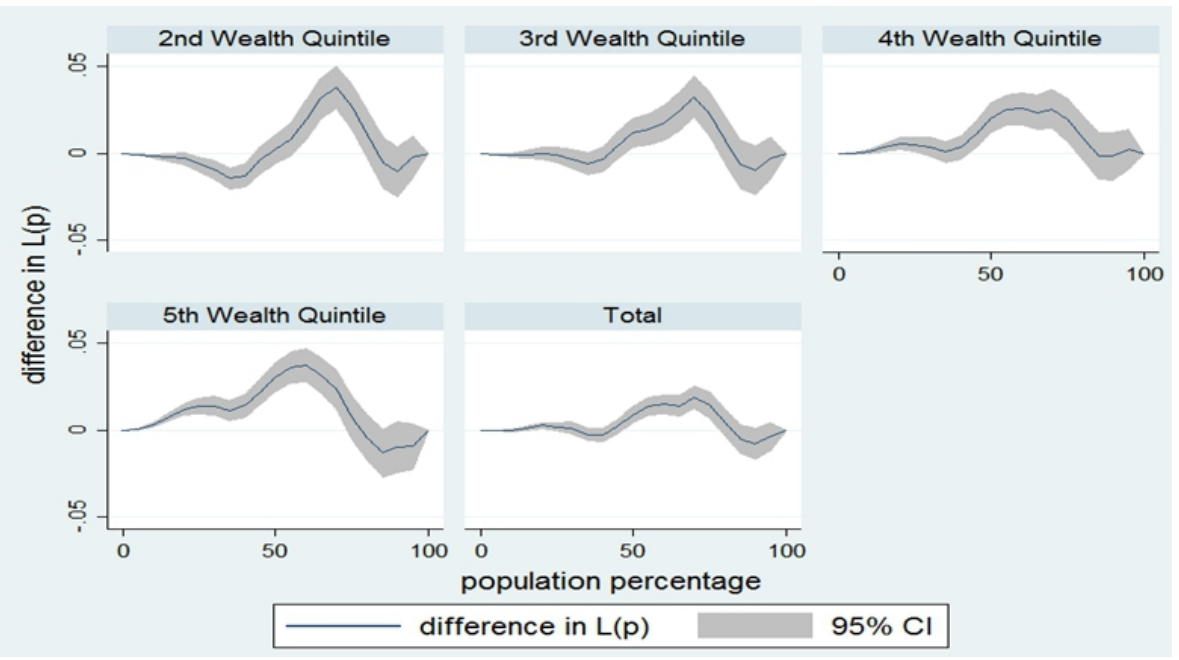

Figure 2: Contrasts and Lorenz dominance of OBA subsidies

From the findings, it is evident that the Lorenz curve of all other wealth quintiles lies above the Lorenz curve of the subsidy beneficiaries in the first wealth quintile. This means that it is positively dominated. The finding clearly shows that OBA subsidy distribution among beneficiaries in the first wealth quintile (poorest women) is unequal when compared with the OBA subsidy distribution to women in other categories of wealth quintiles. This was observed in each category as well as total women considered in the study.

\subsection{Probit regression results}

The estimated marginal effects of the probit models to elucidate the effect OBA subsidies and other covariates on the utilization of family planning and maternal health services. The results are presented in Table 4.

Table 4: Probit marginal effects for family planning and birth deliveries

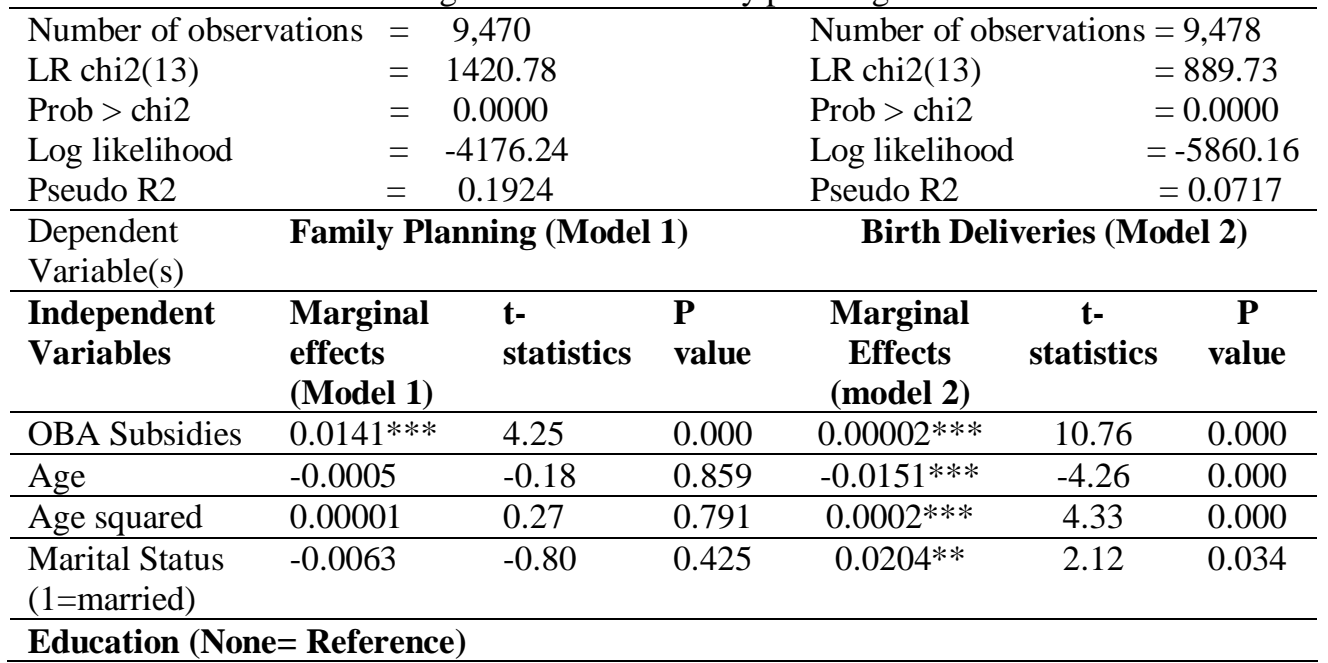




\begin{tabular}{|c|c|c|c|c|c|c|}
\hline Primary & $0.0533 * * *$ & 4.77 & 0.000 & $0.0283 * *$ & 2.09 & 0.037 \\
\hline Secondary & $0.0836 * * *$ & 8.24 & 0.000 & -0.0103 & -0.80 & 0.424 \\
\hline Tertiary & $0.2701 * * *$ & 14.28 & 0.000 & $-0.0499 * *$ & -2.44 & 0.015 \\
\hline \multicolumn{7}{|c|}{ Wealth Quintiles ( $1^{\text {st }}$ Quintile=Reference) } \\
\hline $2^{\text {nd }}$ quintile & $0.0703 * * *$ & 5.61 & 0.000 & $0.2549 * * *$ & 16.85 & 0.000 \\
\hline $3^{\text {rd }}$ quintile & $0.0637 * * *$ & 5.15 & 0.000 & $0.2316 * * *$ & 15.24 & 0.000 \\
\hline $4^{\text {th }}$ quintile & $0.0540 * * *$ & 4.47 & 0.000 & $0.1801 * * *$ & 12.30 & 0.000 \\
\hline $5^{\text {th }}$ quintile & $0.0307 * * *$ & 2.65 & 0.008 & $0.0915 * * *$ & 6.51 & 0.000 \\
\hline Employment & -0.0086 & -0.96 & 0.339 & $0.1208 * * *$ & 11.14 & 0.000 \\
\hline $\begin{array}{l}\text { Exposure to } \\
\text { Mass Media }\end{array}$ & $0.3175 * * *$ & 31.45 & 0.000 & $-0.0817 * * *$ & -7.62 & 0.000 \\
\hline
\end{tabular}

The data reveals that the coefficient on OBA subsidies in model 1 is positive and statistically significant at the $5 \%$ level $(\beta=0.0141, \mathrm{p}<0.000)$. In model 2 , the coefficient on MH $(\beta=0.00002, p<0.000)$ is also positive and statistically significant at $5 \%$ level. This finding indicates that a unit increase in subsidy, increases the probability of uptake of FP by $1.4 \%$ and $0.002 \%$ of the MH care services. The coefficient on age in model $2(\beta=-0.0151, \mathrm{p}<0.000)$ was negative and statistically significant at $5 \%$ level, implying that the probability of giving birth in a clinic decreases with age. However, age squared, increases the probability of using $\mathrm{MH}$ care services. Age squared however does not seem to have influence in the use of FP services (model 1).

Restricting the analysis to wealth quintiles and the use of family planning and maternal health services, the probit regression revealed that women in third wealth quintile $((\beta=0.0637, \mathrm{p}=0.000)$, the fourth wealth quintile $(\beta=0.0540, p=0.000)$ and the fifth wealth quintile $(\beta=0.0307, p$ $=0.008$ ) had a higher probability of utilising $\mathrm{FP}$ and MH services relative to women in the first wealth quintile. In both model 1 and model 2, women in richest wealth quintiles had a higher probability of using family planning and maternal health services than their counterparts in the poorest wealth quintiles.

Also, the results revealed that women who attained primary, secondary, and tertiary education were more likely to use FP services than women with no education at all. The coefficient on primary education $(B=$ 0.0533 , $p$-value $=0.000)$, secondary education $(\beta=0.0836, p=0.000)$ and on tertiary education $(\beta=0.2701, \mathrm{p}$ value $=0.000)$ were positive and statistically significant at the $1 \%$ level. In model 2 , the coefficient on primary education $(\beta=0.0283, p=0.037)$ was positive and statistically at the $5 \%$ level. These results reveal that women who had attained primary level of education had a higher probability of utilizing maternal healthcare compared to those who had no education. For instance, women who had higher education were $4.9 \%$ more likely to use maternal healthcare services compared to those who had no education. 
However, the coefficient on secondary education level was negative and statistically significant at the $5 \%$ level $(\beta=-0.0499, \mathrm{p}$ value $=0.015)$, meaning that women with a higher level of education were less likely to utilise maternal healthcare services under the OBA subsidy programme compared to their counterparts with no education. The results further showed that the probability of utilising family planning and maternal health services was higher among women who had access to health information through mass media compared to those who had no access to health information through mass media.

\section{Discussion of the results}

In line with other studies, the results of this study confirmed that when vouchers are targeted towards poor women who otherwise would not have accessed family planning and maternal health services, they are particularly effective in increasing access to use of family planning and maternal health services, especially among the poor women in traditionally underserved communities (Oyungi et al; 2017; Menotti and Farrell, 2016). The results showed that the OBA voucher subsidy programmes improved access to family planning and maternal health care services. It has been associated with an increase of 1.4 percentage point increase in the probability of using family planning and 0.002 percentage point in the probability of using maternal health services.

The BIA results showed that the degree of inequality among voucher client was quite high with the top $20 \%$ of richest wealth quintile benefitting by $42 \%$ of the OBA subsidies which is progressive to this category. On other hand, the poorest population (the bottom $20 \%$ in the poorest wealth quintile) only benefitted by $4.4 \%$ of the OBA subsidies which is regressive. These results revealed that a substantial proportion, of the OBA subsidy went to the women in the higher wealth quintiles compared to their counter parts in the lower wealth quintiles. Consistent with previous studies of the general population, the analysis of the OBA subsidy revealed disparity in the distribution of the benefits. With the bottom $20 \%$ (80-100) of women in the fifth quintile receiving disproportionately higher benefits compared to the women in the poorest quintile, then the OBA voucher programme was highly regressive.

The probit regression results found that OBA subsidy increased utilisation of family planning and maternal health services among the poor women. For example, the coefficient on OBA subsidies in family planning and maternal health were positive and statistically significant at 5\% level. This demonstrates that the OBA subsidy programme may effectively address barriers to FP and $\mathrm{MH}$ service utilization. The results support the view that voucher schemes can lower inequity in access to healthcare by raising demand 
among the poor more than the non-poor (Ahmed, and Khan, 2011 \& Nguyen et al., 2012).

Targeting effective family planning and maternal health interventions to the most vulnerable especially, in the traditionally underserved community is essential in achieving SDG (Starbird E., et al., (2016). The findings from this study demonstrated that contrary to the intended objective, women in the 2nd, 3rd, 4th and 5 th wealth quintiles (with the fifth quintile being the highest) were more likely to benefit from the OBA subsidy than women in the 1st wealth quintile. The results showed increased uptake of family planning and maternal health services among women in higher wealth quintiles, compared to women in the poorest wealth quintile. The implication of this finding is that even if subsidies removed the cost of services, inability to pay the cost of transport may have prevented women in lower wealth quintiles from utilising the subsidised services. Ir et al., (2010) found that the reasons for non-use of vouchers by recipients was largely due to transportation and intrahousehold constraints. This finding has important implications for policy formulation. To improve the effectiveness of future demand side financing mechanism for subsidizing the price of FP and MH services, policy makers and planners should channel resources toward those most in need of financial subsidy and pay attention to specific barriers affecting those in the lower wealth quintiles.

Studies have showed that higher level of a woman's education is associated with greater knowledge and importance of use of family planning services and risk of home delivery (Jiang and Hardee, 2014). This study found that women who had attained primary, secondary, and tertiary education had significantly higher likelihood of utilizing FP and $\mathrm{MH}$ services compared to women who had no education. There is also likelihood that women with low education are also in the low wealth quintile. The findings give credence to the differential levels of education in the utilisation of family planning and maternal health services. The results from this study are in conformity with the findings from studies conducted in Peru (Weitzman A., 2017); Indonesia (Angeles et al, 2005) and Ghana (Awingura P et al., 2015). These studies underscore the influential role of education in reducing maternal morbidity and highlight the contributions of a woman's education to population health and health transitions. Study protocol for promoting respectful maternity care initiative to assess, measure and design interventions to reduce disrespect and abuse during childbirth in Kenya (Warren et. al., 2013). The study by Apanga and Adam (2015) showed that educated women were more likely to use family planning services as compared their peers who did not receive formal education.

Similarly, the result show that being employment is associated with increased uptake of FP and MH services. This implies that employment is associated with more purchasing power of healthcare services. This finding is 
consistent with the argument that women who are employed, or self-employed are more likely than unemployed women to use family planning services. The coefficient of exposure to mass media was also found to have a significant effect on utilizing FP and MH. Specifically, exposure to mass media increased the likelihood of using family planning by about $26 \%$ and utilising maternal health services by about $43 \%$. These results suggest that exposure to mass media interventions are effective in improving uptake of maternal health care services in limited resource settings.

\section{Conclusion and Policy Recommendations Conclusion}

In conclusion, this study has provided evidence to demonstrate that the voucher programme was not progressive and inequitable, with a predominance of pro-rich use of OBA vouchers. The findings also show that the OBA voucher subsidy programme was associated with increase in women's use of both family planning and maternal health services in the two counties. The study concludes that government should target subsidies to the poorest segment of the population, by ensuring that the indigent benefit more from these subsidies. Recommendations

The study has important implications for health policy and financing of health care services. To increase access to and quality family planning and maternal health services and to universal health coverage (UHC), family planning and maternal health subsidies should be targeted to women in the poorest wealth quintile. The government should ensure that financing subsidies reduce inequities in access and use of family planning and maternal health services.

Given the current debate on healthcare financing, there is need to ensure that the widely advocated Universal Healthcare Coverage (UHC) is progressive. This will provide quality healthcare services for all, as well cushion the low-income earners and poor households from catastrophic health expenditures. This is in line with the study results that shows OBA voucher programme was found to be regressive.

\section{References:}

1. Abuya, T., Njuki, R., Warren, C. E., Okal, J., Obare, F., Kanya, L., \& Bellows, B. (2012). A policy analysis of the implementation of a reproductive health vouchers program in Kenya. BMC Public Health, 12(1), 540.

2. Agha, S. (2011). Changes in the proportion of facility-based deliveries and related maternal health services among the poor in rural Jhang, Pakistan: results from a demand-side financing intervention. International journal for equity in health, 10(1), 57. 
3. Agha, S. (2011). Impact of a maternal health voucher scheme on institutional delivery among low income women in Pakistan. Reproductive health, 8(1), 10.

4. Ahmed, S., and Khan, M. M. (2011). Is demand-side financing equity enhancing? Lessons from a maternal health voucher scheme in Bangladesh. Social science \& medicine, 72(10), 1704-1710.

5. Apanga, P. A., \& Adam, M. A. (2015). Factors influencing the uptake of family planning services in the Talensi District, Ghana. Pan African Medical Journal, 20(1).

6. Akazili, J., Garshong, B., Aikins, M., Gyapong, J., \& McIntyre, D. (2012). Progressivity of health care financing and incidence of service benefits in Ghana. Health policy and planning, 27(suppl_1), i13-i22.

7. Angeles, Gustavo, David K. Guilkey, and Thomas A. Mroz (2005). The Effects of Education and Family Planning Programs on Fertility in Indonesia. Working Paper no. 04-01, Department of Economics, University of North Carolina at Chapel Hill

8. Atanasova, E., Pavlova, M., \& Groot, W. (2016). Out-of-pocket patient payments for public health care services in Bulgaria. Front. Health Care Financing and Affordability in the Emerging Global Markets, 3, 67.

9. Awingura Pascha, Apanga and Ayamba Adam (2015). Factors influencing the uptake of family planning services in the Talensi District, Ghana. The Pan African Medical Journal -ISSN 1937-8688.

10. Barros, A. J., Ronsmans, C., Axelson, H., Loaiza, E., Bertoldi, A. D., França, G. V. \& Victora, C. G. (2012). Equity in maternal, newborn, and child health interventions in Countdown to 2015: a retrospective review of survey data from 54 countries. The Lancet, 379 (9822), 1225-1233.

11. Bellows, B., Kyobutungi, C., Mutua, M. K., Warren, C., \& Ezeh, A. (2012). Increase in facility-based deliveries associated with a maternal health voucher programme in informal settlements in Nairobi, Kenya. Health policy and planning, 28(2), 134-142.

12. Bellows, N. M., Bellows, B. W., \& Warren, C. (2011). Systematic Review: the use of vouchers for reproductive health services in developing countries: systematic review. Tropical Medicine \& International Health, 16(1), 84-96.

13. Bellows, B., Bulaya, C., Inambwae, S., Lissner, C. L., Ali, M., \& Bajracharya, A. (2016). Family planning vouchers in low and middle income countries: a systematic review. Studies in family planning, 47(4), 357-370.

14. Bhutta, Z. A., Hafeez, A., Rizvi, A., Ali, N., Khan, A., Ahmad, F., \& Jafarey, S. N. (2013). Reproductive, maternal, newborn, and child 
health in Pakistan: challenges and opportunities. The Lancet, 381(9884), 2207-2218.

15. Bhargava, A. (2007). Desired family size, family planning and fertility in Ethiopia. Journal of biosocial science, 39(3), 367-381.

16. Kenya National Bureau of Statistics-Kenya and ICF International (2015). 2014 KDHS Key Findings.

17. Demery, L., \& Gaddis, I. (2009). Social Spending, Poverty and Gender Equality in Kenya-A Benefit Incidence Analysis. Eschborn: German Technical Cooperation. Ensor, T. (2004). Consumer-led demand side financing in health and education and its relevance for low- and middle-income countries. The international journal of health planning and management, 19(3), 267-285.

18. Eva, G., Quinn, A., \& Ngo, T. D. (2015). Vouchers for family planning and sexual and reproductive health services: a review of voucher programs involving Marie Stopes International among 11 Asian and African countries. International Journal of Gynaecology \& Obstetrics, 130(S3).

19. Ir, Dirk Horemans, Narin Souk, Wim Van Damme (2010). Using targeted vouchers and health equity funds to improve access to skilled birth attendants for poor women: a case study in three rural health districts in Cambodia. BMC Pregnancy and Childbirth 2010,10:1

20. Grainger, C. G., Gorter, A. C., Al-Kobati, E., \& Boddam-Whetham, L. (2017). Providing safe motherhood services to underserved and neglected populations in Yemen: the case for vouchers. Journal of International Humanitarian Action, 2(1), 6.

21. Jann, B. (2016). Estimating Lorenz and concentration curves. The Stata Journal, 16(4), 837-866.

22. Kakwani, N. C. (1977). Measurement of tax progressivity: an international comparison. The Economic Journal, 87(345), 71-80.

23. KfW, (2012). Vouchers for reproductive health care services in Kenya and Uganda: Approaches supported by financial cooperation. A discussion paper KNBS (2014). Kenya Demographic and Health Survey (2014).

24. Machio, M. P. (2008). Demand for maternal Health care services in Kenya. Unpublished Master of Arts Research Paper). University of Nairobi.

25. Maina, T. M. (2006). Financing and Delivery of Health Care in Kenya: Do the Poor Really Benefit from Public Health Spending? (No. 842006). Institute of Policy Analysis Research.

26. Meuwissen, L. E., Gorter, A. C., \& Knottnerus, A. J. (2006). Impact of accessible sexual and reproductive health care on poor and 
underserved adolescents in Managua, Nicaragua: a quasi-experimental intervention study. Journal of Adolescent Health, 38(1), 56-e1.

27. Jiang Leiwen and Hardee Karen (2014). Women's Education, Family Planning, or Both? Application of Multistate Demographic Projections in India. International Journal of Population Research, Volume 2014, p 9

28. Meyer, C., Bellows, N., Campbell, M., \& Potts, M. (2011). The Impact of Vouchers on the Use and Quality of Health Goods and Services in Developing Countries. A Systematic Review.

29. Menotti EP, Farrell M. Vouchers: a hot ticket for reaching the poor and otherspecial groups with voluntary family planning services. Glob Health SciPract. 2016;4(3):384-93 https://doi.org/10.9745/GHSP-D16-0008

30. Meuwissen, L. E., Gorter, A. C., Kester, A. D., \& Knottnerus, J. A. (2006). Does a competitive voucher program for adolescents improve the quality of reproductive health care? A simulated patient study in Nicaragua. BMC Public Health, 6(1), 204.

31. Murray, S. F., Hunter, B. M., Bisht, R., Ensor, T., \& Bick, D. (2014). Effects of demand-side financing on utilisation, experiences and outcomes of maternity care in low-and middle-income countries: a systematic review. BMC pregnancy and childbirth, 14(1), 30.

32. Mwangangi, M. N. (2017). Demand for reproductive health vouchers and utilization: a case study of output-based approach in Kilifi Kenya. University of Nairobi).

33. Munge, K., \& Briggs, A. H. (2013). The progressivity of health-care financing in Kenya. Health policy and planning, 29(7), 912-920.

34. Myint, A. N. M., Liabsuetrakul, T., Htay, T. T., Wai, M. M., Sundby, J., \& Bjertness, E. (2018). Impoverishment and catastrophic expenditures due to out-of-pocket payments for antenatal and delivery care in Yangon Region, Myanmar: a cross-sectional study. BMJ open, $8(11)$.

35. Ncece, J (2017). Determinants of Contraceptive Uptake among Youth in Kenya: A Case of Turkana County. Unpublished Thesis, University of Nairobi.

36. Nguyen, H. T., Hatt, L., Islam, M., Sloan, N. L., Chowdhury, J., Schmidt, J. O., ... \& Wang, H. (2012). Encouraging maternal health service utilization: an evaluation of the Bangladesh voucher program. Social science \& medicine, 74(7), 989-996.

37. Njuki, R., Abuya, T., Kimani, J., Kanya, L., Korongo, A., Mukanya, C., ... \& Warren, C. E. (2015). Does a voucher program improve reproductive health service delivery and access in Kenya? BMC health services research, 15(1), 206. 
38. Obare, F., Warren, C., Abuya, T., Askew, I., \& Bellows, B. (2013). Population-level impact of vouchers on access to health facility delivery for women in Kenya: a quasi-experimental study. The Lancet, 381, S100

39. Obare, F., Warren, C., Abuya, T., Askew, I., \& Bellows, B. (2014). Assessing the population-level impact of vouchers on access to health facility delivery for women in Kenya. Social science \& medicine, 102, 183-189.

40. O'donnell, O., Van Doorslaer, E., Wagstaff, A., \& Lindelow, M. (2007). Analyzing health equity using household survey data: a guide to techniques and their implementation. The World Bank.

41. Ologunde, R., Maruthappu, M., Shanmugarajah, K., \& Shalhoub, J. (2014). Surgical care in low and middle-income countries: burden and barriers. International Journal of Surgery, 12(8), 858-863.

42. Oyugi, B., Kioko, U., Kaboro, S. M., Gikonyo, S., Okumu, C., OgolaMunene, S, \& Baltazaar, B. (2017). Accessibility of long-term family planning methods: a comparison study between Output Based Approach (OBA) clients verses non-OBA clients in the voucher supported facilities in Kenya. BMC health services research, 17(1), 236.

43. Oyugi, B., Kioko, U., Kaboro, S. M., Okumu, C., Ogola-Munene, S., Kalsi, S. \& Ranji, M. (2018). A facility-based study of women's satisfaction and perceived quality of reproductive and maternal health services in the Kenya output-based approach voucher program. $B M C$ pregnancy and childbirth, 18(1), 310.

44. Richard, L., Furler, J., Densley, K., Haggerty, J., Russell, G., Levesque, J. F., \& Gunn, J. (2016). Equity of access to primary healthcare for vulnerable populations: the IMPACT international online survey of innovations. International journal for equity in health, 15(1), 64.

45. Schellenberg, J. A., Victora, C. G., Mushi, A., De Savigny, D., Schellenberg, D., Mshinda, H., \& Tanzania IMCI MCE Baseline Household Survey Study Group. (2003). Inequities among the very poor: health care for children in rural southern Tanzania. The Lancet, 361(9357), 561-566.

46. Starbird, E., Norton, M., \& Marcus, R. (2016). Investing in family planning: key to achieving the sustainable development goals. Global health: science and practice, 4(2), 191-210.

47. Tulchinsky, T. H., \& Varavikova, E. A. (2014). The new public health. Academic Press. 
48. United Nations Population Fund (2016). Efficiency of sexual and reproductive health spending in Maldives. (UNFPA) ISBN 97899915-54-16-7

49. Weitzman A (2017). The effects of women's education on maternal health: Evidence from Peru. Social Science \& Medicine, Volume 180, May 2017, Pages 1-9

50. Watt, C., Abuya, T., Warren, C. E., Obare, F., Kanya, L., \& Bellows, B. (2015). Can reproductive health voucher programs improve quality of postnatal care? A quasi-experimental evaluation of Kenya's safe motherhood voucher scheme. PLoS One, 10(4), e0122828.

51. Warren, C., Njuki, R., Abuya, T., Ndwiga, C., Maingi, G., Serwanga, J. \& Olenja, J. (2013). Study protocol for promoting respectful maternity care initiative to assess, measure and design interventions to reduce disrespect and abuse during childbirth in Kenya. BMC pregnancy and childbirth, 13(1), 1-9.

52. World Health Organization. (2000). The world health report 2000: health systems: improving performance. World Health Organization.

53. Wu, X. (2008). Maternal Health and Family Size: Evidence from OneChild Policy in China. Manuscript, University of Maryland. 